\begin{tabular}{ll|l} 
Case Reports in & \multicolumn{2}{c}{ Case Rep Gastroenterol 2014;8:26-31 } \\
\cline { 2 - 3 } Gastroenterology & $\begin{array}{l}\text { DOI: 10.1159/000358193 } \\
\text { Published online: January 15, 2014 }\end{array}$ & $\begin{array}{l}\text { ○ 2014 S. Karger AG, Basel } \\
\text { www.karger.com/crg }\end{array}$ \\
\hline & $\begin{array}{l}\text { This is an Open Access article licensed under the terms of the Creative Commons } \\
\text { Attribution-NonCommercial 3.0 Unported license (CC BY-NC) (www.karger.com/OA- } \\
\text { license), applicable to the online version of the article only. Distribution permitted for non- } \\
\text { commercial purposes only. }\end{array}$
\end{tabular}

\title{
Pancreatic Arteriovenous Malformation
}

\author{
Takumi Yamabuki $^{\mathrm{a}}$ Masanori Ohara ${ }^{\mathrm{a}}$ Noriko Kimura ${ }^{\mathrm{b}}$ \\ Kunishige Okamura ${ }^{a}$ Aki Kuroda ${ }^{a}$ Ryo Takahashi ${ }^{a}$ Kazuteru Komuro ${ }^{a}$ \\ Nozomu Iwashiro ${ }^{a}$ \\ Departments of ${ }^{a}$ Surgery and ${ }^{b}$ Pathology, National Hospital Organization Hakodate \\ Hospital, Hakodate, Japan
}

\section{Key Words}

Arteriovenous malformation · Pancreas · Distal pancreatectomy

\begin{abstract}
An unusual case of pancreatic arteriovenous malformation (P-AVM) combined with esophageal cancer is reported. A 59-year-old man was admitted with upper abdominal pain. Contrast-enhanced computed tomography showed numerous strongly enhanced abnormal vessels and a hypovascular lesion in the area of the pancreatic tail. Angiographic study of the celiac artery confirmed racemose vascular networks in the tail of the pancreas. Endoscopic retrograde pancreatography revealed narrowing and displacement of the main pancreatic duct in the tail of the pancreas. Screening esophagoscopy showed a 0-IIa+IIc type tumor in the lower thoracic esophagus. Histological examination of esophagoscopic biopsies showed squamous cell carcinoma. Based on these findings, P-AVM or pancreatic cancer and esophageal cancer were diagnosed. Video-assisted thoracoscopic esophagectomy and distal pancreatectomy were performed. Histological examination of the resected pancreas revealed abundant abnormal vessels with intravascular thrombi. In addition, rupture of a dilated pancreatic duct with pancreatic stones and both severe atrophy and fibrosis of the pancreatic parenchyma were observed. The final diagnoses were P-AVM consequent to severe chronic pancreatitis and esophageal carcinoma. The patient's postoperative course was relatively good.

(c) 2014 S. Karger AG, Basel
\end{abstract}

T. Yamabuki, MD PhD

Department of Surgery

National Hospital Organization Hakodate Hospital

18-16 Kawahara-cho, Hakodate 041-8512 (Japan)

E-Mail bukiyama@themis.ocn.ne.jp 
Yamabuki et al.: Pancreatic Arteriovenous Malformation

\section{Introduction}

An arteriovenous malformation (AVM) is a complex tangle of abnormal arteries and veins linked by one or more direct connections called fistulas or shunt. AVM can occur anywhere in the body. An increasing number of patients with AVM in the digestive organs are being diagnosed due to widespread use of imaging techniques, but pancreatic AVM (P-AVM) is a very rare disease. To the best of our knowledge, fewer than 70 cases with this disease have been reported in the English language literature.

Many cases of P-AVM are associated with Rendu-Osler-Weber syndrome and are known to be a part of the visceral angiodysplasia of hereditary hemorrhagic telangiectasia. The majority of patients with P-AVM remain asymptomatic, but some present with abdominal pain or gastrointestinal bleeding. The most frequently involved portion of the pancreas has been reported to be the head (59.4\%), followed by the body and tail (33.3\%) and the entire pancreas $(7.2 \%)$ [1]. The definitive treatment for P-AVM is surgical resection. A case of P-AVM with esophageal cancer who underwent distal pancreatectomy and esophagectomy is presented, and the relevant literature is reviewed.

\section{Case Report}

A 59-year-old man was admitted to our hospital with intermittent upper abdominal pain. He had a history of cervical disc herniation, lumbar compression fracture and abdominal aortic aneurysm. Physical examination revealed slight tenderness in the left upper quadrant of the abdomen, and no masses were palpable. Laboratory data on admission showed: erythrocyte count $411 \times 10^{4} / \mathrm{mm}^{3}$ (normal 410-530), hemoglobin $13.7 \mathrm{~g} / \mathrm{dl}$ (normal 14-18), leukocyte count $9,800 / \mathrm{mm}^{3}$ (normal 4,000-8,000), platelet count $27.1 \times$ $10^{4} / \mathrm{mm}^{3}$ (normal 15-40), serum total protein $6.8 \mathrm{~g} / \mathrm{dl}$ (normal 6.5-8.0), total bilirubin $0.67 \mathrm{mg} / \mathrm{dl}$ (normal 0.2-1.0), aspartate aminotransferase $16 \mathrm{IU} / \mathrm{l}$ (normal 10-40), alanine aminotransferase 12 IU/l (normal 5-40), alkaline phosphatase 339 IU/l (normal 115-360), lactate dehydrogenase $256 \mathrm{IU} / \mathrm{l}$ (normal 119-229), $\gamma$-glutamyltranspeptidase 56 IU/l (normal 10-47), serum amylase $100 \mathrm{U} / \mathrm{l}$ (normal 33-116), blood urea nitrogen $14.0 \mathrm{mg} / \mathrm{dl}$ (normal 8-22), creatinine $0.8 \mathrm{mg} / \mathrm{dl}$ (normal $0.6-1.1$ ), and C-reactive protein $1.71 \mathrm{mg} / \mathrm{dl}$ (normal 0-0.3). The serum level of the tumor marker carcinoembryonic antigen (CEA) was slightly elevated to $6.5 \mathrm{ng} / \mathrm{ml}$ (normal 0-5), and the carbohydrate antigen (CA19-9) level was elevated to $159.3 \mathrm{U} / \mathrm{ml}$ (normal 0-37).

Contrast-enhanced computed tomography (CT) showed numerous strongly enhanced abnormal vessels and a hypovascular lesion in the area of the pancreatic tail (fig. 1a). Angiographic study of the celiac artery confirmed racemose vascular networks in the tail of the pancreas and early venous return to the portal system (fig. 1b). Endoscopic retrograde pancreatography (ERP) revealed narrowing and displacement of the main pancreatic duct in the tail of the pancreas (fig. 1c). Screening esophagoscopy showed a 0-IIa+IIc type tumor in the lower thoracic esophagus and multiple Lugol-voiding lesions. Histological examination of esophagoscopic biopsies showed squamous cell carcinoma.

Based on these findings, P-AVM and chronic pancreatitis or pancreatic cancer with esophageal cancer were diagnosed. Video-assisted thoracoscopic esophagectomy and distal pancreatectomy with partial transverse colectomy were performed. The operative time was $402 \mathrm{~min}$, and the amount of blood loss was $956 \mathrm{ml}$. There was a honeycomb-like structure with collected vessels in the pancreas. The splenic vein was occupied by thrombi (fig. 2). 
Yamabuki et al.: Pancreatic Arteriovenous Malformation

Histological examination of the resected pancreas revealed rupture of the dilated pancreatic duct with bleeding (fig. 3a), pancreatic stones (fig. 3b) and severe atrophy with fibrosis of the pancreatic parenchyma (fig. 3c). These findings were consistent with chronic pancreatitis. In addition, many abnormal vessels, some containing thrombi, were observed in the pancreas (fig. 3d). The final diagnosis was P-AVM consequent to severe chronic pancreatitis and esophageal carcinoma. The patient had an uneventful postoperative course, and CA19-9 levels normalized to $27.6 \mathrm{U} / \mathrm{ml}$.

\section{Discussion}

P-AVM is a very rare condition. Fewer than 70 cases with this disease have been reported in the English language literature since the first report of P-AVM by Halpern et al. in 1968 [2]. A review of AVM by Meyer et al. [3] revealed that 78\% of AVMs were located in the cecum and right colon, whereas only $0.9 \%$ were located in the pancreas.

The etiology of P-AVM is classified into congenital and acquired. About $90 \%$ of patients with P-AVM are thought to be the congenital type, including patients with Rendu-OslerWeber syndrome. The acquired type is usually secondary to inflammation, tumor or trauma $[4,5]$. In the present case, there was no family history of Rendu-Osler-Weber syndrome and no telangiectasia; however, histological evidence of chronic pancreatitis was found. Therefore, it was thought to be an acquired case secondary to chronic inflammation.

P-AVM is frequently associated with symptoms of abdominal pain and gastrointestinal bleeding. Aida et al. [6] classified the mechanism of gastrointestinal bleeding into the following five types: (1) bleeding from esophagogastric varices secondary to portal hypertension; (2) bleeding from the AVM to the pancreatic duct; (3) bleeding from the AVM to the bile duct; (4) bleeding from intestinal mucosa in contact with the AVM; (5) bleeding from a duodenal ulcer associated with the AVM. So-called steal syndrome may cause abdominal pain, with shunting of blood away from the mesenteric circulation through the AVM [7].

Song et al. [1] showed the efficacy of contrast-enhanced dynamic CT as the first-line method for the diagnosis of P-AVM. The CT findings suggested that the characteristic features of P-AVM included strong enhancement or conglomeration of small hypervascular spots in the lesion and early contrast filling of the portal vein. Angiographic study is useful for the diagnosis of P-AVM and subsequent interventional therapy. The findings of P-AVM are characterized by dilated and tortuous feeding arteries, with a racemose vascular network, followed by a transient dense pancreatic stain and early venous filling. Kanno et al. [8] suggested that the diagnosis of this disease be confirmed by angiography. However, these findings can be seen in pancreatitis or hypervascular neoplasms such as cystadenoma, cystadenocarcinoma, angiosarcoma and islet cell tumor [5]. In addition, the procedure is relatively invasive. Koito et al. [9] discussed the usefulness of color Doppler ultrasonography for the detection of P-AVM, which was reported to be almost equal to that of angiography; however, it is difficult to identify the feeding arteries with ultrasonography [10]. In the present case, contrast-enhanced CT showed numerous strongly enhanced abnormal vessels, but a hypovascular region was present in the area of the pancreatic tail. ERP revealed narrowing and displacement of the main pancreatic duct in the tail of the pancreas. The serum level of the tumor marker CA19-9 was elevated to $159.3 \mathrm{U} / \mathrm{ml}$. Based on these findings, pancreatic cancer was considered in the differential diagnosis.

According to a recent review of 69 P-AVMs, 46.4\% underwent pancreatic resection, $10.1 \%$ were treated by extended devascularization, and $15.9 \%$ were treated by transcatheter arterial embolization (TAE). Despite a small number of cases, irradiation therapy after 
Yamabuki et al.: Pancreatic Arteriovenous Malformation

TAE due to recurrent bleeding and a transjugular intrahepatic portosystemic shunt (TIPS) has been reported [1]. P-AVM has multiple feeding arteries; therefore, it is very difficult to ligate or embolize them all. If no treatment is given, a P-AVM will grow and cause portal hypertension, gastrointestinal bleeding or rupture of esophageal varices [1, 5]. Furthermore, it has been reported to be impossible to reduce portal hypertension, once established, even if the AVM is surgically removed [4]. Therefore, surgical resection of the affected pancreatic lesion at an early stage is needed for complete cure of P-AVM. TAE, irradiation therapy and TIPS are options for high-risk surgical patients.

In summary, to the best of our knowledge, we have described for the first time a case of $\mathrm{P}-\mathrm{AVM}$ combined with esophageal cancer. P-AVM is a very rare disease, but should be considered in the differential diagnosis of a hypervascular pancreatic lesion.

\section{Disclosure Statement}

The authors have no funding or conflicts of interest to disclose.

\section{References}

1 Song KB, Kim SC, Park JB, Kim YH, Jung YS, Kim MH, Lee SK, Lee SS, Seo DW, Park do H, Kim JH, Han DJ: Surgical outcomes of pancreatic arteriovenous malformation in a single center and review of literature. Pancreas 2012;41:388-396.

2 Halpern M, Turner AF, Citron BP: Hereditary hemorrhagic telangiectasia. An angiographic study of abdominal visceral angiodysplasias associated with gastrointestinal hemorrhage. Radiology 1968;90: 1143-1149.

-3 Meyer CT, Troncale FJ, Galloway S, Sheahan DG: Arteriovenous malformations of the bowel: an analysis of 22 cases and a review of the literature. Medicine (Baltimore) 1981;60:36-48.

4 Nishiyama R, Kawanishi Y, Mitsuhashi H, Kanai T, Ohba K, Mori T, Hamabe N, Watahiki Y, Nakamura S: Management of pancreatic arteriovenous malformation. J Hepatobiliary Pancreat Surg 2000;7:438-442.

5 Chang S, Lim HK, Lee WJ, Choi D, Jang KT: Arteriovenous malformation of the pancreas in a patient with gastrointestinal bleeding: helical CT findings. Abdom Imaging 2004;29:259-262.

-6 Aida K, Nakamura H, Kihara Y, Abe S, Okamoto K, Otsuki M: Duodenal ulcer and pancreatitis associated with pancreatic arteriovenous malformation. Eur J Gastroenterol Hepatol 2002;14:551-554.

7 Makhoul F, Kaur P, Johnston TD, Jeon H, Gedaly R, Ranjan D: Arteriovenous malformation of the pancreas: a case report and review of literature. Int J Angiol 2008;17:211-213.

-8 Kanno A, Satoh K, Kimura K, Masamune A, Asakura T, Egawa S, Sunamura M, Watanabe M, Shimosegawa T: Acute pancreatitis due to pancreatic arteriovenous malformation: 2 case reports and review of the literature. Pancreas 2006;32:422-425.

-9 Koito K, Namieno T, Nagakawa T, Ichimura T, Hirokawa N, Mukaiya M, Hirata K, Hareyama M: Congenital arteriovenous malformation of the pancreas: its diagnostic features on images. Pancreas 2001;22:267-273. Ogawa H, Itoh S, Mori Y, Suzuki K, Ota T, Naganawa S: Arteriovenous malformation of the pancreas: assessment of clinical and multislice CT features. Abdom Imaging 2009;34:743-752. 


\begin{tabular}{l|l}
\hline Case Rep Gastroenterol 2014;8:26-31 \\
\hline DOI: 10.1159/000358193 & $\begin{array}{l}\text { ○ 2014 S. Karger AG, Basel } \\
\text { www.karger.com/crg }\end{array}$ \\
\hline
\end{tabular}

Yamabuki et al.: Pancreatic Arteriovenous Malformation
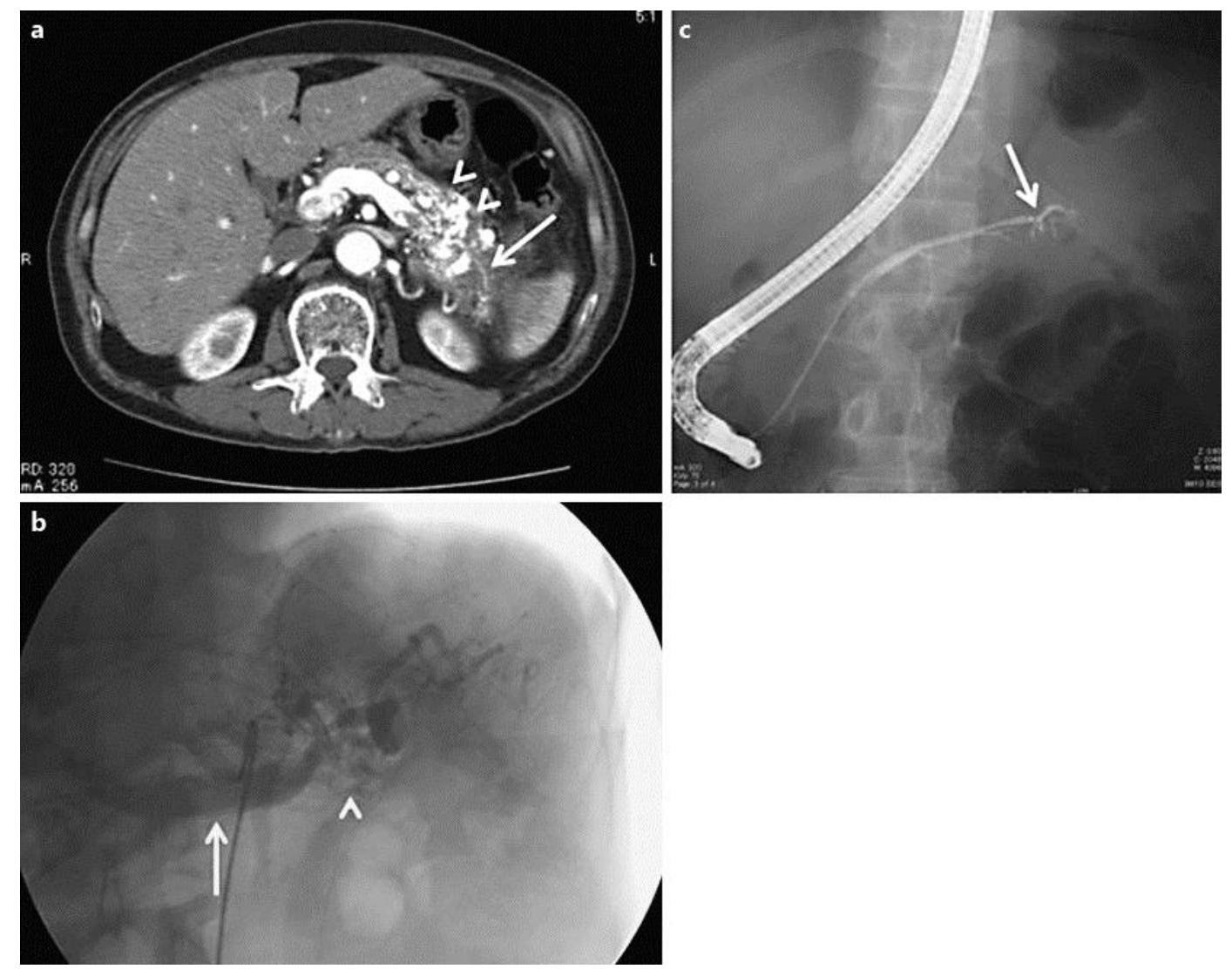

Fig. 1. a Contrast-enhanced CT showed numerous strongly enhanced abnormal vessels (arrowheads) and a hypovascular lesion in the area of the pancreatic tail (arrow). b Angiographic study of the celiac artery confirmed racemose vascular networks in the tail of the pancreas (arrowhead) and early venous return to the portal system (arrow). c ERP showed narrowing and displacement of the main pancreatic duct in the tail of the pancreas (arrow). 


\begin{tabular}{rl|l} 
Case Reports in & \multicolumn{2}{l}{ Case Rep Gastroenterol 2014;8:26-31 } \\
\cline { 2 - 3 } Gastroenterology & DOI: 10.1159/000358193 & $\begin{array}{l}\text { C 2014 S. Karger AG, Basel } \\
\text { www.karger.com/crg }\end{array}$ \\
\cline { 2 - 3 } &
\end{tabular}

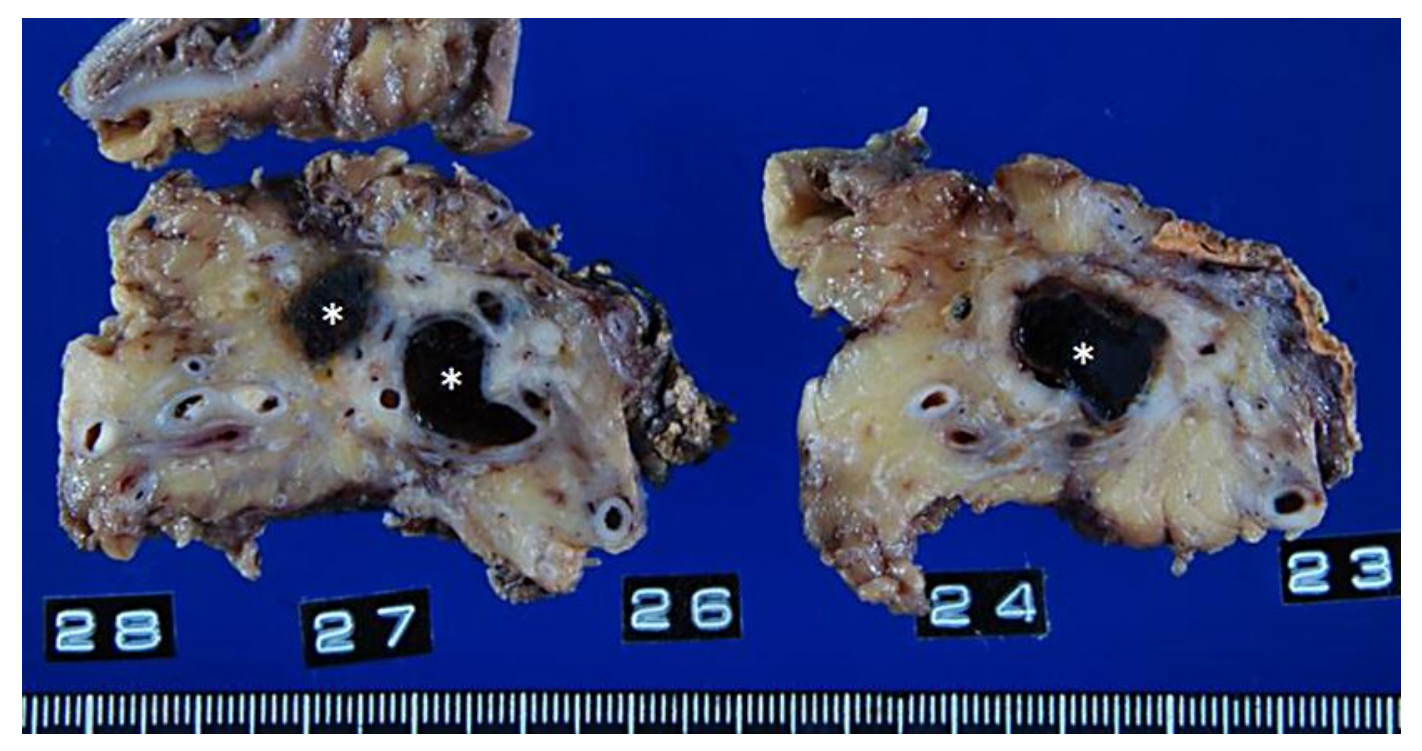

Fig. 2. A honeycomb-like structure with collected vessels was observed in the pancreas. The splenic vein was occupied by thrombi (asterisks).
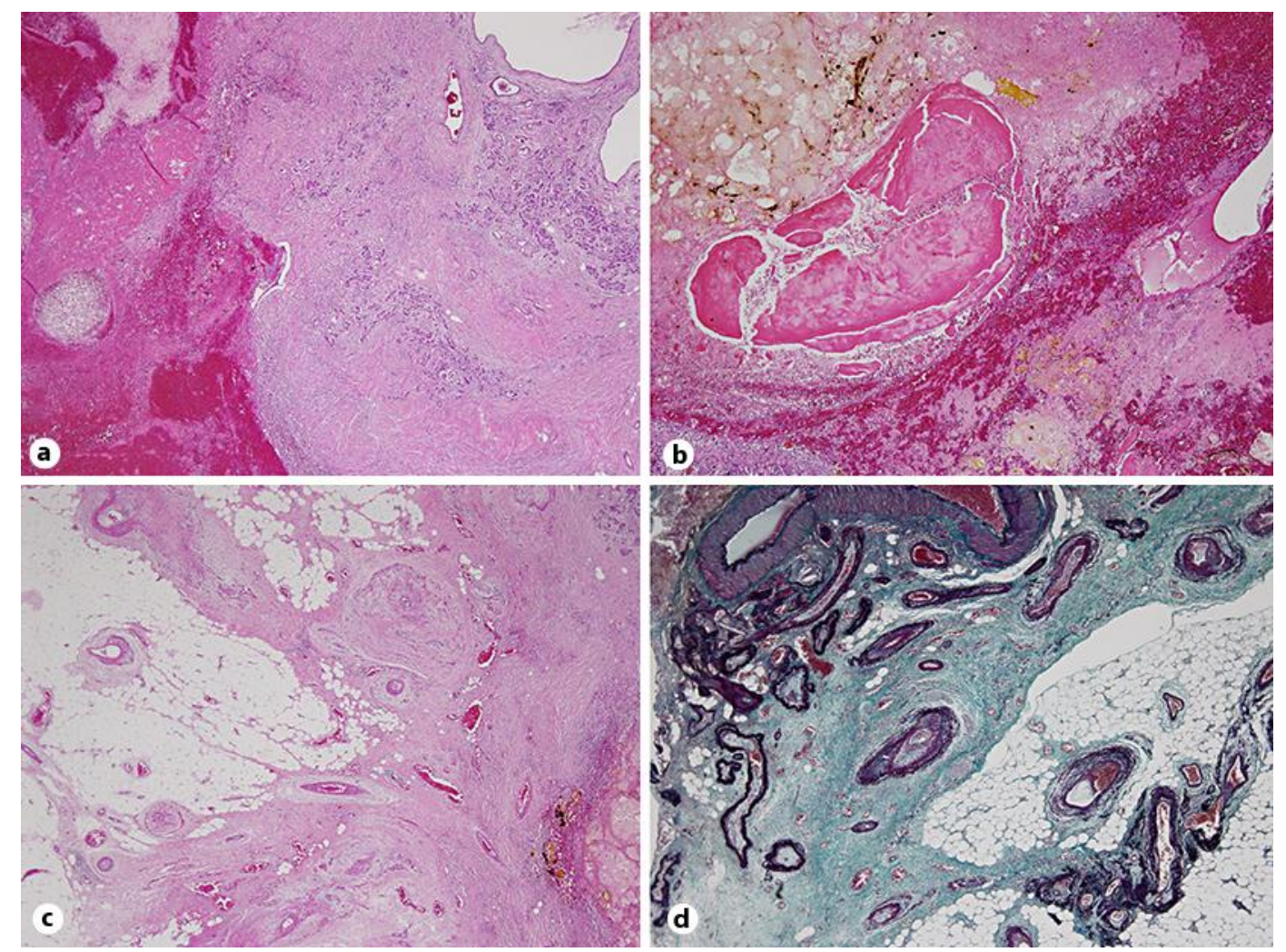

Fig. 3. a Histological examination of the resected pancreas showed rupture of the dilated pancreatic duct with bleeding $(\mathrm{HE}, \times 10)$. b Pancreatic stones $(\mathrm{HE}, \times 10)$. c Severe atrophy with fibrosis of the pancreatic parenchyma $(\mathrm{HE}, \times 10)$. d Abundant abnormal vessels were observed in the pancreas, some containing thrombi (Elastica van Gieson, $\times 10$ ). 